\title{
Performance of Hearing-Impaired Children with Hearing Aid and Cochlear Implant in Auditory Verbal Therapy
}

\author{
Spoorthy Shivaprakash ${ }^{1 *}$ and Nerea Ortega Castro ${ }^{2}$ \\ ${ }^{1}$ School of Advanced Education Research and Accreditation (SAERA), Castellón de la Plana, Spain \\ ${ }^{2}$ Department of Psychology, Universidad Loyola Andalucía, Sevilla, Spain
}

*Corresponding author: Spoorthy Shivaprakash, School of Advanced Education Research and Accreditation (SAERA), Castellón de la Plana, Spain

\begin{abstract}
A Cochlear Implant (CI) is a surgically implanted device, which is a small but complex device that helps a severe-profoundly deaf individual to hear the sound. Inner ear is the innermost region in the human ear that consists of Cochlea, Balance system and the Auditory nerve; in which Cochlea is the most important part of the Inner ear. Once the sound reaches the inner ear, the cochlea transforms the sound waves into electrical impulses that are sent through the Auditory nerve to the brain. The cochlear implant restores the inner ear functions and the acoustic consciousness of pre and postlingually deaf individuals is increased. The hearing aid is an electronic device that comes in different styles that are worn behind the ear and few are worn inside the ear. The comparison is done with Behind the Ear (BTE) hearing aids. The scientific literature is reviewed on the performance of hearing impaired children with BTE hearing aids and CI. The performance is compared with the BTE hearing aids, as the children with severe-profound hearing loss are fitted with BTE hearing aids due to its wide dynamic range characteristic. The comparison is made for right ear, left ear and bilateral. 'Categories of Auditory Performance' (CAP) test was performed on a group of children wearing BTE hearing aids and CI as it is performed on both wearing BTE hearing aids and CI. The comparison was also made with high frequency sounds, level of understanding and with the duration of therapy attended. The available data show a great benefit with $\mathrm{CI}$ as compared to Hearing Aid from the results measured. The post-implant linguistic performance is critically affected by several variables. The full development of linguistic competence is allowed by CI and marked benefits in a wide range of psychological and social abilities is provided, whereas with Hearing Aid the children may have delayed language or the command on language may be imperfect.
\end{abstract}

\section{Introduction}

Humans at birth, and even before in utero, are prepared to acquire and learn speech and language from their environment [1]. Language acquisition and production is maximized by the early interactions with the environment and gives humans the opportunity to process sounds. Mainly, hearing is what helps these interactions possible. Auditory perception is closely related to interactions between human biological mechanisms and their environment from the time sound reaches the utero to until a single word is uttered. Language acquisition is also related to other domain developments; like motor and cognitive development, etc. since, when speech is not achieved, children tend to use gestures to express and fulfill their needs. Language acquisition is a combination of experiencedependent and independent mechanisms. Neural mechanisms and innate factors may be responsible for the interaction between the listening experience, the listening environment and the interpretation of environmental information. For some children, the normal development of language is disturbed by lack of acoustic

feedback and essential auditory information, and from auditory deprivation. For some deaf children, the artificial stimulation of the auditory system provides them with an opportunity to acquire verbal skills. Hearing aids are small wearable electronic devices, which enable a person to hear sounds better and understand speech more clearly providing an overall improvement in communication ability. The Hearing Aid functions as follows: Sound is first taken in through a miniature microphone where the sound is converted into an electronic digital signal. Then, the signal is processed, amplified and modified according to the needs of the user and his hearing loss. Finally, a receiver, which is a miniature loudspeaker, sends the processed sound through the type of ear fitting/ear mould, which is appropriate for your hearing aid system. A CI is a neuroprosthetic device that is surgically implanted which provides a person with severe-profound sensorineural hearing loss a sense of sound. The CI has two major parts, the internal part, which acts as the receiver, and an external part that acts as a speech processor. 
Cochlear implantation and hearing aids help to hear and acquire language, and the present study focuses on the comparison of the performance between Cochlear implants and hearing aids. Several hearing aids are made with certain electroacoustic properties which includes frequency response, saturation sound pressure level and various aspects of compression [2]. With the application of universal newborn hearing screening programs and the rapid increase in birthing facilities conducting UNHS, the average age of identification of newborns with hearing loss over the last 20 years has decreased from approximately 30 months of age [3] to approximately 6 months of age. The identification of infants and young children having hearing loss at an earlier age has increased and those who do not receive appropriate rehabilitation are likely to have delayed language, cognition, and social-emotional development than their hearing peers. When infants who have hearing loss or are deaf receive treatment before six months of age, they typically maintain language development with their cognitive abilities until 5 years of age [4] Amplification is a method that consists of increasing the sound volume in a device like in the case of hearing aids, amplifiers inbuilt inside the hearing aid performs the function of amplification. Amplification is considered the most important intervention to help children with hearing loss. Amplification will provide children the ability to access residual hearing, so that their speech and language could be developed at or near age-appropriate milestones. Amplification for infants and young children may not enable children with hearing loss to perform at the level consistent with their normal hearing peers in all situations. The goal of amplification for children with hearing loss is to help them with their speech audibility at a comfortable level, and to provide them with as many acoustic cues as possible, without over-amplifying sounds, especially those sounds that are loud. Hearing aid fitting has to be done at a proper/earlier age or else the children would face problems in developing language, as there would be no sound input to the child, and thus results in poor speech intelligibility. As the child will not be given with proper amplification, there is a lack in learning appropriate language at a correct age and consequently it results in poor language development and poor speech intelligibility. A study was conducted [5], where different groups of children were taken based on the age of hearing aid fitting ( $<6$ months old, $>6$ months, 2 years and 3 years) and were checked for speech intelligibility. The result was that the group of children fitted during their first 6 months of life had much better speech intelligibility as compared with other group of children fitted later in life. We can place in the amplification protocol into these following six steps, which are carried on one after the other in a sequence:

a) Taking ear impressions/obtaining ear molds.

b) Measuring the real ear coupler difference (RECD).

c) Using a prescriptive approach to determine target hearing aid gain and output.

d) Choosing the hearing aid.

e) Verifying the chosen instruments.

f) Fitting the devices and providing a follow-up schedule.
This protocol can be simplified into these steps:

a) Assessment

b) Selection

c) Verification

d) Validation

Auditory handicap of hearing impairment happens when there is very limited usage from the hearing aids. There is already loss of a sense that the individual faces and thus gets the help of the amplification device. Therefore, if the amplification device gives a minimum help or minimum benefit the outcome will be negative. The hearing aid has to be beneficial during understanding of speech; if this is attenuated, the hearing aids can help by compensating the loss and helping them to hear. Nevertheless, if there is reduction in both speech signal and noise, the hearing aids are not beneficial. The minimum amount of handicap they could have is $24 \mathrm{~dB}$ [6]. The individual has to be satisfied with the amplification device. They need to get acclimatized to the changes they are facing within and from the environment after wearing the hearing aid. Cognition plays a very important role in this; better cognitive abilities allows individuals get more benefit with hearing aids as compared to those with low cognitive abilities [7]. The major topic that includes cognition is Top-Down (TD) and Bottom-Up (BU) systems. Top-down (TD) systems receive, evaluate, and interpret bottom-up (BU) input. TD systems assign meaning. They determine psychological and emotional composition, and include cognition, executive functions, speech, language and auditory processing, and other self-driven analyses and interpretations. BU systems transfer and transmit "raw" externally derived sensory input (light, temperature, sound, smells, pressure, etc.) to the central auditory nervous system. The hearing loss plays a very significant role in the quality of life. Individuals with hearing loss usually report a greater rate of depression and greater feelings of social isolation than those who do not have hearing loss [8]. Other emotional issues of the hearing-impaired individuals include anger and withdrawal [9]. So, hearing loss usually results in poor mental health. Listening is influenced by listener's characteristics influences such as motivation, expectations and personality.

In case of children, the child has to be motivated to hear, as it becomes the most essential part of living, as it has its future based completely over that from learning the language, studies, etc. Only if the innate communication capabilities are acknowledged and treated upon, the cognitive development of children with Hearing Impairment will be similar to that of normal hearing children. In case of congenital deafness, the parents' feelings of guilt and sorrow has to be checked upon during the prenatal diagnosis and during the first few months. Parents should be provided with psychological support, as it is important for them to accept the child, since he or she is developing and to overcome the unexpected loss. The child has to be trained to perceive the existence of sounds, and visual contact has to be encouraged. The parents should show lot of affection and care towards the child, and physical and gestural contact should be maintained in abundance. As behavioral psychology states, learning mainly occurs through environmental stimuli. As the children grow 
and start with their schooling, the hearing aid has to help them in different ways. The hearing aid technology has to help in difficult to listen situations like in classroom, market, etc., as the amount of noise is excessive, which results in poor understanding of speech, and hence results in poor communication. Current hearing aids are designed to face the difficult to listen situations, and therefore includes several technologies like directional microphones, noise reduction, and fast acting amplitude compression systems. Signal processing depends on working memory and is designed to improve speech understanding that may have positive and negative consequences [10]. As we move on further with the different technologies for children with hearing loss, we have the Cochlear Implant (CI), which is a surgically implanted neuro-prosthetic device that helps for the severe-profound hearing-impaired children to hear and acquire language. The development of auditory speech perception, speech production, and language skills are affected in children having profound hearing loss. Some children having profound hearing loss develop good oral communication skills with conventional hearing aids but most fail to. The reason for some children to develop communication skills with hearing aids is that the aided performance with the hearing aid falls within the speech range (speech banana: the speech banana is a region where all the phonemes of the world's language fall on an audiogram), and therefore the child gets benefitted with the hearing aid. If the child fails to develop adequate oral communication skills, it can have significant negative effect on the education of the child.

The multichannel cochlear implants are recognized by the American Academy of Audiology in 1990 [11] as sensory aid options for children with profound hearing loss who have limited or no functional benefit from conventional hearing aids amplification. Multichannel cochlear implants are useful for children with congenital or acquired hearing loss. Further, the parents (or legal guardian) have the right to choose a cochlear implant if they decide that it is the most appropriate option for their child. In one of the studies conducted [12] it was observed that the children who were implanted at age <2.5years, there was a greater improvement in consonant speech production and vocabulary outcomes. As age increases, the rate of learning and improvement decreases. Hearing-impaired adults and children who wear hearing aids and cochlear implants provide an opportunity to examine the direction and characteristics of plasticity in the central auditory system. Plasticity is the ability of the brain to reorganize itself by forming new connections between brain and cells (neurons). A period of maximal synaptogenesis in the auditory cortex is the sensitive period in the early childhood [13]. Sensitive period is a time or stage in a person's development when they are more responsive to certain stimuli and quicker to learn particular skills, like for children the sensitive period for the development of Central Auditory System in children is 3.5 years or less. Implantation within this sensitive period provides the children with the opportunity of the auditory experience needed for the improvement of essential synaptic pathways. Generally, the changes in P1 cortical auditory evoked potential taken up in humans after the CI gives us an impression about the re-organization and plasticity in children. The P1 component of the cortical auditory evoked potential (CAEP) shows clearly documented age-related decreases in latency and changes in morphology in normal hearing children, providing a biomarker for development of the auditory cortical pathways in humans.

Early implantation will be plasticity, and consequently it helps in proper organization and cortex development. Cortical development is based on learning through stimulation. In case of congenital hearing loss, the absence of sensory input from birth affects normal growth and the connectivity of the functional sensory system, resulting in a lack of oral language learning. Cochlear implants bypass cochlear damage by directly stimulating the auditory nerve and brain, and consequently many of the deleterious effects of sensory deprivation are avoided. There is a sensitive period for the development of central auditory system in children and it is 3.5 years or less. As observed by Sharma et al. [14], plasticity is higher at this age, and as a result learning is increased in this period. For some, up to 7 years old plasticity will be present, but it is usually reduced by 3.5 years or above it. To learn words and acquire language, children must be able to discriminate and correctly perceive phonemes. Early word learning and speech perception skills have different sensitive periods. The very early implantation may affect later vocabulary outcomes more than the speech perception outcomes. Early implantation $(<3.5$ years old) gives a good central auditory evoked potentials (CAEP), and P1 latency while that of late implanted ( $>7$ years old) shows decrease in the waveforms. If both ears are simultaneously implanted, there is a good development in language skills as well, but when a child is being implanted for one ear at $<3.5$ years old and other ear at $>7$ years old, it shows different CAEP waveforms and P1 latency [15]. Age appropriate linguistic competence development is a goal for the educational programs for children who are hard of hearing. The role of language competence in the development of education is important for the children with hearing loss, as they have to match with their peers in school. Language competence also helps them to build their social skills, for their constructive thinking in this world and in several other crucial domains. If early intervention during 'critical period' for speech development is not given, then the child gets handicapped. This handicap is characterized by poor speech comprehension and language communication. Cochlear implantation helps to improve auditory perception in severe to profound hearing-impaired children. Auditory skills of hearingimpaired children are variable due to different etiologic factors.

The reasons for the hearing loss vary from one individual to another and thus affects the child's auditory skills and learning. Children implanted with Cochlear Implant have good listening skills, and this consequently helps in learning the language. There is a significant improvement in the language with Cochlear implanted children by attending regular Auditory Verbal Therapy (AVT) sessions [16]. Auditory-verbal therapy is a method for teaching hearing-impaired children to listen and speak using their residual hearing in addition to the constant use of amplification devices such as hearing aids, FM devices, and cochlear implants. AuditoryVerbal practice emphasizes listening to auditory information, and thus helps the children to develop intelligible speech and 
spoken language. Auditory-Verbal practice supports the one-toone diagnostic therapy and involves the parent participation, guidance, education and support by an Auditory-Verbal specialist. The AVT is given three times or two times in a week for around 45 minutes to 1 hour for almost 3 years. The major goal of AVT is to enable children with hearing loss to grow up in regular learning and living environments, and helps them to become independent, participating and contributing citizens in the society. As early hearing impairment restricts a child to learn to speak and listen without the use of gestures to communicate, AVT helps the child to learn to speak with the help of regular Auditory Verbal Therapy [17]. AVT was found to be highly effective method in the language development and accelerating the spoken language. Regular and effective AVT helps in the correct development of language skills [18]. Parental involvement is a crucial part in child's learning and takes many forms that is good parenting at home, provision of a safety and stable environment, intellectual stimulation, parentchild discussion, constructive social and educational values and high values relating to become a good citizenship, participation in school events, participation in the work of the school, and participation in school governance. The family social class, maternal and paternal level of education, maternal and paternal psychosocial health and single parent status and family ethnicity influences parental involvement. Children implanted at a very young age have the capability to achieve nearly normal language skills after AVT sessions. However, this is not achieved only with the therapy given at the therapy center, but rather it has to be followed regularly at home by parents. Therefore, the parents have to be guided, educated, and counseled regarding the steps to be followed at home for the development of child's speech and language skills [19]. AVT has proved to be a successful intervention for Hearing Impaired children, [20] though a certain group might not have been useful with the AVT. Just by attending the AVT sessions, it is not possible to have a very good improvement, but home training given by parents is very essential and gives a much better improvement in their speech and language skills. The rate of language growth in children with CI through AVT is comparatively faster. Intervention program has helped many children to achieve age appropriate language skills, and when compared with their peer group age, the language skills were almost similar. Based on the time spent in the intervention program, it is suggested that the more time spent; the greater was the contribution to language growth [21].

\section{Hearing Aids}

\section{What is a Hearing Aid?}

Hearing aids are small wearable electronic devices, which enable a person to hear sounds better and understand speech more clearly providing an overall improvement in communication ability. Different signal processing strategies implemented in modern digital Hearing Aid are explained. Algorithms ranging from dynamic-range compression and directional microphones to sound classification and binaural noise suppression are clearly explained. Processing strategy is accompanied by a summary of its effectiveness [22].

\section{Function of Hearing Aid}

Sound is first taken in through a miniature microphone where it is converted into an electronic digital signal. Then, the signal is processed, amplified and modified according to the needs of the user and his hearing loss. Finally, a receiver, which is a miniature loudspeaker, sends the processed sound through the type of ear fitting/ear mould, which is appropriate for your hearing aid system. The major disadvantage with hearing aids is that its properties are related to noise reduction. Background noise is particularly damaging to speech intelligibility for people with hearing loss. They used many simple techniques ranging from relatively simple forms of filtering to advanced signal processing methods. Nontechnical language issues are involved, and various approaches are conducted to solve the problem [23]. The presence, or threat, of acoustic feedback has long been one of the major problems in the fitting and wearing of hearing aids. Acoustic feedback occurs when some of the amplified sound leaks from the ear canal and is picked up by the hearing aid microphone and then re-amplified.

Different techniques have been investigated to reduce this effect like by using adaptive notch filter, novel method for feedback cancellation with adaptation during quiet intervals. Based on the study they suggest that novel system provides the best overall performance [24]. The improvement in terms of signal to ratio (SNR) which is the primary factor for speech intelligibility in background noise is provided by directional microphone of digital hearing aids, which relatively enhances sensitivity of microphones to signals arriving from front direction than other. A study was done with different reverberation time and having monaural/binaural hearing aids with directional/omnidirectional microphones. The result was that the signal to noise ratio is optimized when binaural hearing aids with directional microphones are used in rooms with short reverberation times [25].

\section{Performance of a Hearing Aid}

The microphone of hearing aid picks up the sound from the environment and the sound is passed to the external ear, then to the middle ear, then to the inner ear and Auditory nerve. The transmission takes a longer route and hence for the patient with severe-profound hearing loss, the sound reaching the inner ear is not very much audible and hence the interpretation by the Auditory nerve is not very clear. Here it depends on the anomaly of the parts of the inner ear and depending on that, the resultant listening graph may change. Majorly, in severe-profound hearing-impaired children the hair cells corresponding to high, mid and low frequencies will be absent (preserving some of the low frequency hair cells).

\section{Cochlear Implant}

\section{What is a Cochlear Implant?}

A CI is a neuroprosthetic device that is surgically implanted which provides a person with severe-profound sensory-neural hearing loss a sense of sound. CIs bypass the normal acoustic hearing process, instead replacing it with electric hearing. A prosthesis was required for the profoundly hearing-impaired 
individuals; hence, a lot of engineering work was involved in the development of the prosthetic device and its parts. Many different specialists were involved, in which the most important seemed to be the rehabilitationist, wherein they mentioned regarding the methods, goal set, etc. Finally, it was implanted in the individuals and the functioning was checked further along with rehabilitation [26].

\section{Function of a Cochlear Implant}

It mainly consists of two parts:

a) Internal part which is the Receiver.

b) External part which is the Speech processor.

\section{Internal part}

The internal part is implanted surgically and has a receiver and tiny electrodes. The receiver is imbedded under the skin behind the ear. The electrode array is inserted into the cochlea.

\section{External part}

The external portion, which is called the speech processor can, comes in variety of sizes and wearing options. Cochlear implants help the hearing impaired to listen better by receiving and processing sounds and speech. The sound is changed into electrical signals that in turn stimulate the hearing nerve and this change is worked together by the internal and external devices. First, the microphone located on the external device picks up the sound. Then the speech processor filters, analyzes, and converts the sound into a digital code. The signal is then sent, where it is transmitted across the skin to the internal receiver, via radio frequencies through the cable to the headpiece. The signal is being distributed to the electrodes along the array by the internal receiver, which has been placed inside the cochlea. The electrodes that stimulate the auditory nerve, which is connected to the cochlea, send the tiny electrical charges. As the CI stimulates the auditory nerve directly, it bypasses the damaged parts of the cochlea that cause hearing loss. The electrical signals to the brain are carried by the auditory nerve where they are interpreted as sound. This process occurs so fast that the listener hears the speech and other sounds without any delay.

CI users can achieve very good speech understanding, though there can be great differences in outcomes that is partially accounted by age, residual hearing, and duration of hearing loss. The Cochlear Implant individuals with high performance in speech recognition performed better as the number of channels increased. Nevertheless, the CI individuals with low performance in speech recognition did not have any better performance even if the channels increased [27]. In one of the studies, different strategies in the methodology were observed and one strategy that is compressed analogue (CA) strategy processor users were taken and were checked for performance. There was large improvement in the scores of speech reception tests for all subjects [28]. The sound localization in the auditory system and better understanding of speech in noisy situations are achieved with binaural hearing when the source of speech and noise are presented from different locations in the horizontal plane. Sound localization in the horizontal plane relies on two binaural cues: Interaural level difference (ILD) and Interaural time difference (ITD). Bilateral implantation has greater benefit in localization and lateralization. It helps in speech perception in noise as well as quiet. In a study, when the performances of ILD and ITD were tested, ILD seemed to be much better compared to that of ITD [29]. Binaural integration is likely to influence the performance with CI and Hearing Aid. In presence of noise, speech was not audible or difficult to identify with Hearing Aid. Whereas, with CI speech was audible and was understood [30].

\section{Performance of a Cochlear Implant}

In $\mathrm{CI}$, the microphone picks up the sound from the environment and is directly sent through the Auditory nerve bypassing other parts of the ear including external ear, middle ear and inner ear and if cochlea has any sorts of anomaly it would be bypassed. The information is heard faster and hence interpreted faster and without much hassle. When the child starts with speech therapy and listening training, the information travels faster and helps the child to learn and understand concepts faster.

\section{Guidelines for Determining Candidacy for a Cochlear Implant}

The critical factor in the determination of implant candidacy is the accurate assessment of hearing impairment by an audiologist. An age-appropriate combination of behavioral and physiological measures has to be used by the audiologist to determine hearing status of the child. A pure tone audiogram, acoustic reflex data and if needed, auditory brainstem responses to both clicks and tonal stimuli has to be performed before confirming bilateral severeto-profound sensorineural hearing loss. Behavioral audiological tests should be performed to provide appropriate electroacoustic amplification and training. After the child has had a sufficient trial with hearing aid amplification, a cochlear implant is indicated. The audiological criteria for implantation is when the child has congenital or acquired profound sensorineural hearing loss (A pure tone average $(500,1000,2000 \mathrm{~Hz})$ of $90 \mathrm{~dB} \mathrm{HL}$ or greater in both ears is indicated) and limited or no functional benefit from electroacoustic hearing aid amplification. The limited benefit from functional hearing aid is by the performance results of pediatric multichannel cochlear implant users. Hearing aid benefit is put up in terms of:

i. Aided thresholds with conventional hearing aids relative to aided results in the high frequencies where important consonants occur, and

ii. Performance on word recognition tasks, administered with auditory cues only in a closed- or open-response set.

The selection of the ear to be implanted is chosen based on Transtympanic promontory stimulation. Candidates for cochlear implantation require medical evaluation by an otolaryngologist, including history, physical examination and imaging studies of the temporal bone. The patient should be free of active ear disease, have an intact tympanic membrane, and be acceptable candidate for general anesthesia. High resolution computed tomography (CT) 
scan, magnetic resonance imaging (MRI), or both, are necessary to identify the implantable cochlea and patent internal auditory canal. When auditory nerve integrity is in doubt, electrical promontory stimulation is indicated. The implant components and function, the risks, limitations, and potential benefits of implantation, the surgical procedure, and the postoperative follow-up schedule should be discussed with parents (or guardians), and the child, if age appropriate. The child has to be educated based on the use of auditory prostheses and the development of auditory and speech skills. It is further recommended that parents (or guardians), and the child, if age appropriate, be fully informed about alternatives to implantation.

\section{Auditory-Verbal Therapy \\ What is Auditory-Verbal Therapy}

AVT is a specialized type of therapy to teach a child to use the hearing provided by a hearing aid or a cochlear implant for understanding speech and learning to talk. The child is taught to hear and have intelligible speech. An integral part of communication, recreation, socialization, education and work by Hearing and active listening. The goal of AVT is helping the hard of hearing children to grow up in a regular learning environment, helping them to become independent, participating, and contributing citizens in the society. AVT encourages the use of naturalistic conversation and the use of spoken language to communicate and is a parent centered approach. It is a method that emphasizes on the use of residual hearing and helps children learn to listen, process verbal language, and speak AVT maximizes the use of the child's aided residual hearing for the detection of sound and to acquire language. The common language delays associated with hearing impairment is reduced by early identification of hearing loss with immediate fitting with amplification, as well as prompt intervention. The parents are taught during their child's individual therapy sessions, are asked to emphasize on residual hearing, and are taught to interact with their child using the auditory-verbal approach. With normalhearing peers, AVT encourages from the beginning the interaction and mainstreaming of children. Participation in playgroups and in community schools can provide children high motivation for the natural language models. AVT teaches the child to develop selfmonitoring skills. The natural voice quality is promoted as the child learns to listen to his/her own voice as well as to others during natural conversations. The parent, therapist, and child engage in play activities that teach the child to use his or her amplified residual hearing to learn auditory-verbal communication like children with normal hearing. In a study the author, [31] emphasizes on the development of the child in speech and language after the optimal fitting of the audiological devices. When there is residual hearing, the first intervention comes AVT and then diagnostic teaching. Parents are assisted to create a listening environment.

\section{How it is Different from Speech Therapy}

Speech therapy is majorly corresponding to the language taught using lip movement/visual cues. The child is encouraged to lip read and learn to speak the language with the correct production of individual sound. The child is encouraged to learn through visual cues. It does not encourage the child to hear. Speaking using simple language. Parents are majorly observers. It can be practiced ingroup sessions. It is mainly through drill based. In AVT, the child is encouraged to learn language mainly through child's listening abilities. It is majorly learning through listening. Listening has high expectations. The child is made to achieve clear speech. Natural language is provided. Parents play the role of teachers. The child has to be given individual therapy. It's mainly conversation based.

\section{Importance of Auditory-Verbal Therapy}

Children with even profound hearing losses can detect most of the speech most if not all, when aided properly. A child who has a hearing impairment has to be an auditory learner and need not automatically be a visual learner (i.e., sign language). Children learn language in a supportive environment most effectively through consistent meaningful learning interactions. As verbal language is developed through audition, reading skills are also developed. In AVT programs, parents are not taught sign language. AVT uses and encourages the maximum use of hearing, and stresses listening rather than visual cues. AVT uses a team approach to therapy that allows for a more complete education environment. Auditory Verbal Therapy has proved to be effective for children with hearing loss. With respect to speech, language and self-esteem there was no much difference between the groups taken [32]. Early identification of Hearing Impairment helps in early intervention. Therefore, it further helps to start the AVT early.

It helps them to grow up in regular living and learning environment so that they all can become independent individuals participating and contributing in the society [33]. In a study conducted, every child was tested for different outcomes after the implantation with the help of AVT. Several multi-center researches required to get the correct impression regarding the AVT intervention [34]. The focus of AVT comprises of intensive early intervention therapy sessions on audition, technological management and involvement of the child's caregivers in therapy sessions; it is the only therapy approach, which has avoidance or exclusion of non-auditory visual communication. The primary goal of AVT is to achieve age-appropriate spoken language. AVT programs are expanded and are present throughout the world but little evidence is found on the effectiveness of the intervention. AVT has shown a significant benefit for school aged children and good improvement in speech and language skills. Therefore, it shows that not just in the initial years, AVT is required but also during the later stages, that is, during school age. Therefore, it shows that continuous AVT/Rehabilitation is required for better performance [35].

\section{Methods}

\section{Research Objectives}

The objective of the current study is to check the performance of children implanted with CI and children fitted with Hearing Aid in AVT. The following areas were assessed:

a) Understand the difference in performance in AVT for the two groups of children wearing $\mathrm{CI}$ and Hearing Aid using CAP. 
b) Understand the difference in the level of understanding of the concept taught in AVT.

c) Understand the difference in the ability to hear highfrequency sounds.

d) Understand the effect of the duration of therapy attended by children wearing CI and Hearing Aid.

\section{Inclusion Criteria}

a) subjects were taken who were implanted with $\mathrm{CI}$ at the same time, same age (approx.) and having the same degree of hearing loss.

b) 3 subjects were taken who were fitted with Hearing Aid at the same time, same age (approx.) and having the same degree of hearing loss.

c) All subjects were children between the age of 3 years to 4 years.

d) All participants had severe-profound hearing loss.

e) All the subjects had pure sensorineural pathology.

\section{Exclusion Criteria}

a) Children having mild, moderate and moderately-severe degree of hearing loss were excluded.

b) Children having normal hearing sensitivity were excluded.

c) Children with mixed hearing loss or with Middle ear pathology were excluded.

d) Children with poor mental abilities were excluded (like: Mental retardation, Autism, etc).

e) Teenagers and Adults with severe-profound hearing loss were excluded.

\section{Comparison of performance with Cochlear Implant and Hearing Aid using CAP}

A group (A) of 3 subjects who were implanted with Cochlear Implant (CI) were taken having the same degree of hearing loss, same age (approximately) and same time at which CI was implanted and Auditory Verbal Therapy was started at the same time which is as shown in Table 1.

Table 1: Case details of group 'A' subjects.

\begin{tabular}{|c|c|c|c|c|}
\hline Cases & Hearing aid/CI & Gender & Age of Subject & Duration of Therapy Attended \\
\hline Case 1 & CI & Female & 3 years 5 months & 1 year \\
\hline Case 2 & CI & Male & 3 years & 10 months \\
\hline Case 3 & CI & Male & 3 years & 11 months \\
\hline
\end{tabular}

\section{Background}

\section{Case 1}

The child was brought to this clinic with a complaint of delayed speech and language development secondary to hearing loss. The child was born through normal delivery in a private hospital. The parents reported no other significant history (it was a full term delivery with immediate birth cry and correct birth weight). Detailed audiological evaluation (Pure tone Audiometry, Immittance, and Auditory reflex) was done and the child was diagnosed with bilateral severe to profound hearing loss. The case underwent cochlear implantation for right ear and left ear simultaneously. The child is a Bilateral Kanso user. The child attends 2 sessions/week regularly for 45 minutes to 1 hour. The duration of the therapy was 1 year.

\section{Case 2}

The child was brought to this clinic with a complaint of delayed speech and language development secondary to hearing loss. The child was born through caesarian delivery in a private hospital. The child had low birth weight and no other significant history (it was a full-term delivery with immediate birth cry) was reported by the parents. Detailed audiological evaluation (Pure tone Audiometry,

Table 2: Case details of group ' $B$ ' subjects.
Immittance, and Auditory reflex) was done and the child was diagnosed with bilateral severe to profound hearing loss. The case underwent simultaneous cochlear implantation for both ears. The child is a Bilateral Kanso user. The child attends 2 sessions/week regularly for 45 minutes to 1 hour. The duration of the therapy was 10 months.

\section{Case 3}

The child was brought to this clinic with a complaint of delayed speech and language development secondary to hearing loss. The child was born through normal delivery in a private hospital. The parents reported no other significant history (it was a full term delivery with immediate birth cry and correct birth weight). Detailed audiological evaluation (Pure tone Audiometry, Immittance, and Auditory reflex) was done and the child was diagnosed with bilateral severe to profound hearing loss. The case underwent simultaneous cochlear implantation. The child is a Bilateral Kanso user. The child attends 2 sessions/week regularly for 45 minutes to 1 hour. The duration of the therapy was 11 months. - A group (B) of three subjects who were fitted with hearing aid were taken having the same degree of hearing loss, same age (approximately) and same time at which Hearing aid was fitted and Auditory Verbal Therapy was started at the same time which is as shown in Table 2.

\begin{tabular}{|c|c|c|c|c|}
\hline Cases & Hearing aid/CI & Gender & Age of Subject & Duration of Therapy Attended \\
\hline Case 1 & CI & Female & 3 years 5 months & 1 year 1 month \\
\hline Case 2 & CI & Male & 3 years & 11 months \\
\hline Case 3 & CI & Male & 3 years & 10 months \\
\hline
\end{tabular}




\section{Case 4}

The child was brought to this clinic with a complaint of delayed speech and language development secondary to hearing loss. The child was born through caesarian delivery in a private hospital. The parents reported no other significant history (it was a full term delivery with immediate birth cry and correct birth weight). Detailed audiological evaluation (Pure tone Audiometry, Immittance, and Auditory reflex) was done and the child was diagnosed with bilateral severe to profound hearing loss. The case was fitted with hearing aids for the right ear and left ear simultaneously. The child attends 2 sessions/week regularly for 45 minutes to 1 hour. The duration of the therapy was 1 year and 1 month.

\section{Case 5}

The child was brought to this clinic with a complaint of delayed speech and language development secondary to hearing loss. The child was born through caesarian delivery in a private hospital. The child had delayed birth cry and no other significant history (it was a full-term delivery with normal birth weight) was reported by the parents. Detailed audiological evaluation (Pure tone Audiometry, Immittance, and Auditory reflex) was done and the child was diagnosed with bilateral severe to profound hearing loss. The case was fitted with hearing aids for both the ears simultaneously. The

\section{Table 3: CAP FORM.}

child attends 2 sessions/week regularly for 45 minutes to 1 hour. The duration of the therapy was 11 months.

\section{Case 6}

The child was brought to this clinic with a complaint of delayed speech and language development secondary to hearing loss. The child was born through normal delivery in a private hospital. The parents reported no other significant history (it was a full term delivery with immediate birth cry and correct birth weight). Detailed audiological evaluation (Pure tone Audiometry, Immittance and Auditory reflex) was done and the child was diagnosed with bilateral severe to profound hearing loss. The case was fitted with hearing aids for both ears simultaneously. The child attends 2 sessions/week regularly for 45 minutes to 1 hour. The duration of the therapy was 10 months. Having all the characteristics similar, child's intelligence quotient (IQ) level, Cognitive skills, Intellectual skills. Home training may vary from individual to individual.

\section{Categories of Auditory Performance (CAP)}

Categories of Auditory Performance (CAP) is an index consisting of eight performance categories arranged in order of increasing difficulty. The test starts with sounds, words, phrases and then sentences. Both the ears can be tested with the same test which is as shown in Table 3 [36].

\begin{tabular}{|c|c|c|c|c|}
\hline Level & Auditory performance (without lip-reading) & \multicolumn{3}{|c|}{ Score } \\
\hline \multicolumn{2}{|r|}{ Condition } & Left & Right & Bilateral \\
\hline 0 & $\begin{array}{l}\text { No awareness of environmental sounds or voice } \\
\text { The professional has not observed any functional awareness of environmental sounds or of voice at any time or } \\
\text { been given any report of such awareness. }\end{array}$ & & & \\
\hline 1 & $\begin{array}{l}\text { Awareness of environmental sounds } \\
\text { The professional has observed spontaneous reaction to at least five different environmental sounds in the home } \\
\text { or in naturalistic environment. Reports given by others may be taken into account, but the professional must have } \\
\text { witnessed some reactions. }\end{array}$ & & & \\
\hline 2 & $\begin{array}{l}\text { Response to speech sounds } \\
\text { The client is observed responding to a speech sound. Any response is acceptable such as pausing during an activity, } \\
\text { looking at a conversational partner and smiling, or looking around, providing it is clearly a response to the sound } \\
\text { that is made. The client will demonstrate this by carrying out an action in response to a speech signal given at } \\
\text { normal conversational speech level from 0.5-1 meter. }\end{array}$ & & & \\
\hline 3 & $\begin{array}{l}\text { Identification of environmental sounds } \\
\text { The child is consistently able to identify at least } 5 \text { sounds, e.g. a doorbell, telephone in the everyday environment. } \\
\text { This means that they make a consistent and specific response to each particular sound.eg going to the door if the } \\
\text { doorbell rings. }\end{array}$ & & & \\
\hline 4 & $\begin{array}{l}\text { Discrimination of speech sounds without lipreading } \\
\text { The client is reliably able to discriminate between two speech sounds. These may be, but do not have to be the Ling } \\
\text { sounds. For a young child this may be observed whilst looking at a book, they may imitate animal noises made by } \\
\text { an adult e.g., "sssss for snake". }\end{array}$ & & & \\
\hline 5 & $\begin{array}{l}\text { Understands common phrases e.g., "open the door"; "push the car" without lip-reading } \\
\text { The child can identify simple familiar commands in known contexts and / or is able to correctly point to a picture in } \\
\text { a book. An older child may be able to complete a Closed Sentence Test. }\end{array}$ & & & \\
\hline 6 & $\begin{array}{l}\text { Understanding of conversation without lip-reading } \\
\text { A child is able to have a simple conversation without being reliant on lip-reading. }\end{array}$ & & & \\
\hline 7 & $\begin{array}{l}\text { Use of telephone with known speaker } \\
\text { The client is able to hold an unscripted conversation with a known person on the telephone. They must be able to } \\
\text { answer simple questions, e.g., "What are you doing?" without the conversation breaking down. }\end{array}$ & & & \\
\hline 8 & $\begin{array}{l}\text { Follows group conversation in reverberant room where there is some interfering noise such as a classroom } \\
\text { or a restaurant } \\
\text { The client is able to follow a conversation within a group knowing which speaker is talking and what is being said } \\
\text { in an environment with interfering noise, e.g., a classroom discussion or a discussion at a restaurant. }\end{array}$ & & & \\
\hline
\end{tabular}




\section{Therapeutic Approach}

a) The therapy is given in a closed soundproof room in which the clinician sits beside the child and AVT is given. The parent will be present, is involved in the therapy sessions so that they understand the procedure of therapy, and helps them with home training.

b) Different materials will be used like flash cards, models, toys, etc., in order to teach a concept to the child.

c) The concept is taught by introducing a single object (e.g., apple) in the form of model first and then is taught by telling its name. Then in a more natural situation by showing the real 'apple' and describing its color, shape, taste, etc. Similarly, it is taught in the same way for all the objects in every topic.

d) There are 6 major levels in AVT

i. Auditory Awareness level.

ii. Auditory Discrimination level.

iii. Auditory Identification level.

iv. Auditory Memory and Sequencing level.

v. Auditory Comprehension level.

vi. Auditory Cognition level.

e) One subject from each group was taken and was tested for the level of AVT in which they were already trained. All the students from both the groups were tested.

f) For e.g., Different topics of Auditory Identification were taken as:

i. Ling's sounds: /a/, /i/, /u/, /m/, /s/, /sh/

ii. Nouns: Fruits, Vehicles, Body parts, Colors, etc.

iii. Verbs: Sitting, Eating, Running, Sleeping, Drinking, etc.

iv. Prepositions: Above, Below, Inside, Outside, Besides, etc.

\section{Comparison of Level of Understanding of Concepts for CI and Hearing Aid}

All the six cases were made to identify the nouns and verbs with the help of respective flash cards presented in front of them only through auditory mode in a closed soundproof room where the clinician sits beside the child and AVT is given. These are individual therapy sessions. The results were noted in terms of trials which is as shown in Table 5.

\section{Comparison of performance for $\mathrm{CI}$ and Hearing Aid with high frequency sounds}

All the six cases were made to identify the six ling sounds only through auditory mode in a closed soundproof room where the clinician sits beside the child and AVT is given. These are individual therapy sessions. The results were noted in terms of trials which is as shown in Table 6.

\section{Results}

The individual ear is first tested (right ear and left ear) and then both the ears (bilateral).

Table 4: The following are results using CAP.

\begin{tabular}{|c|c|c|c|}
\hline \multirow{2}{*}{ Cases } & \multicolumn{3}{|c|}{ Cap score } \\
\cline { 2 - 4 } & Right Ear & Left Ear & Bilateral \\
\hline Case 1 & 4 score & 4 score & 5 score \\
\hline Case 2 & 4 score & 4 score & 4 score \\
\hline Case 3 & 3 score & 4 score & 5 score \\
\hline Case 4 & 3 score & 3 score & 3 score \\
\hline Case 5 & 3 score & 3 score & 4 score \\
\hline Case 6 & 2 score & 3 score & 3 score \\
\hline
\end{tabular}

Table 5: The following are the results for the 'level of understanding',

\begin{tabular}{|c|c|c|}
\hline \multirow{2}{*}{ Cases } & \multicolumn{2}{|c|}{ Level of Understanding } \\
\cline { 2 - 3 } & Nouns & Verbs \\
\hline Case 1 & $5 / 5$ trials & $4 / 5$ trials \\
\hline Case 2 & $4 / 5$ trials & $3 / 5$ trials \\
\hline Case 3 & $4 / 5$ trials & $4 / 5$ trials \\
\hline Case 4 & $4 / 5$ trials & $2 / 5$ trials \\
\hline Case 5 & $3 / 5$ trials & $1 / 5$ trials \\
\hline Case 6 & $2 / 5$ trials & $0 / 5$ trials \\
\hline
\end{tabular}

Table 6: The following are the results for the high frequency sounds.

\begin{tabular}{|c|c|c|c|c|c|c|}
\hline \multirow{2}{*}{ Cases } & \multicolumn{6}{|c|}{ Ling's Six Sounds } \\
\hline & /a/ & /i/ & $/ \mathbf{u} /$ & $/ \mathrm{m} /$ & $/ \mathrm{s} /$ & /sh/ \\
\hline Case 1 & $\begin{array}{c}5 / 5 \\
\text { trials }\end{array}$ & $\begin{array}{c}5 / 5 \\
\text { trials }\end{array}$ & $\begin{array}{c}5 / 5 \\
\text { trials }\end{array}$ & $\begin{array}{c}5 / 5 \\
\text { trials }\end{array}$ & $\begin{array}{l}5 / 5 \\
\text { trials }\end{array}$ & $\begin{array}{c}5 / 5 \\
\text { trials }\end{array}$ \\
\hline Case 2 & $\begin{array}{c}5 / 5 \\
\text { trials }\end{array}$ & $\begin{array}{c}5 / 5 \\
\text { trials }\end{array}$ & $\begin{array}{l}5 / 5 \\
\text { trials }\end{array}$ & $\begin{array}{c}5 / 5 \\
\text { trials }\end{array}$ & $\begin{array}{c}4 / 5 \\
\text { trials }\end{array}$ & $\begin{array}{c}4 / 5 \\
\text { trials }\end{array}$ \\
\hline Case 3 & $\begin{array}{c}5 / 5 \\
\text { trials }\end{array}$ & $\begin{array}{c}5 / 5 \\
\text { trials }\end{array}$ & $\begin{array}{l}5 / 5 \\
\text { trials }\end{array}$ & $\begin{array}{c}5 / 5 \\
\text { trials }\end{array}$ & $\begin{array}{c}4 / 5 \\
\text { trials }\end{array}$ & $\begin{array}{c}5 / 5 \\
\text { trials }\end{array}$ \\
\hline Case 4 & $\begin{array}{l}5 / 5 \\
\text { trials }\end{array}$ & $\begin{array}{c}5 / 5 \\
\text { trials }\end{array}$ & $\begin{array}{l}5 / 5 \\
\text { trials }\end{array}$ & $\begin{array}{c}4 / 5 \\
\text { trials }\end{array}$ & $\begin{array}{c}3 / 5 \\
\text { trials }\end{array}$ & $\begin{array}{c}4 / 5 \\
\text { trials }\end{array}$ \\
\hline Case 5 & $\begin{array}{l}5 / 5 \\
\text { trials }\end{array}$ & $\begin{array}{c}4 / 5 \\
\text { trials }\end{array}$ & $\begin{array}{l}5 / 5 \\
\text { trials }\end{array}$ & $\begin{array}{c}4 / 5 \\
\text { trials }\end{array}$ & $\begin{array}{c}2 / 5 \\
\text { trials }\end{array}$ & $\begin{array}{c}3 / 5 \\
\text { trials }\end{array}$ \\
\hline Case 6 & $\begin{array}{l}5 / 5 \\
\text { trials }\end{array}$ & $\begin{array}{c}4 / 5 \\
\text { trials }\end{array}$ & $\begin{array}{c}4 / 5 \\
\text { trials }\end{array}$ & $\begin{array}{c}3 / 5 \\
\text { trials }\end{array}$ & $\begin{array}{c}1 / 5 \\
\text { trials }\end{array}$ & $\begin{array}{c}2 / 5 \\
\text { trials }\end{array}$ \\
\hline
\end{tabular}

\section{Discussions}

The first objective was to understand the difference in the performance in AVT for the two groups of children wearing CI and Hearing Aid using CAP. The results in Table 4 shows that, the CAP scores are higher for $\mathrm{CI}$ as compared to that for Hearing Aid. The CI implanted children have better scores for individual ear and hence 
helps the child to comprehend and express language in a much easier way as compared to that of children implanted with Hearing Aid. The children with $\mathrm{CI}$ take much lesser time to learn language as compared to that of children fitted with hearing aid. A study was conducted [37] on a group of children wearing CI and hearing aid, where they were made learn English language and it was observed that CI participants performed much better than the participants wearing hearing aid in the acquisition of English language. This supports the current study that the performance with $\mathrm{CI}$ is better than performance with hearing aid. The second objective was to understand the difference in the level of understanding the concept taught in AVT. The results from Table 5 shows that the amount of time taken by CI children to learn language (nouns and verbs) is much lesser as compared to children with hearing aids.

Hence, the speech production, the intelligibility and the language of children with $\mathrm{CI}$ is much better than children with hearing aids. In a study [38], they assessed the novel-word learning by varying word forms, stimulus level and observed that the children with hearing aid scored $41 \%$ when compared to normal hearing children who scored $60 \%$ in the same test. The third objective was to understand the difference in the ability to hear the high frequency sounds. The results from Table 6 shows that the scores obtained for the ling sounds /s/ and /sh/ are much lesser as compared to other ling sounds. Thus, which clearly shows that the children with hearing aids have difficulty listening to these high frequency sounds, which in turn affects them in the production of these sounds. These affect the children with hearing aids in the articulation of the high frequency words and hence the intelligibility is reduced as compared to that of children with CI. In a study [39], a group of children wearing $\mathrm{CI}$ and hearing aid were compared with the overall intelligibility, articulation, resonance and voice and found that the children with CI had much better intelligibility as compared to children with hearing aid. It was even observed that children with hearing aid had more phonetic and phonological disorders. This supports the current study that CI implantees perform better than children with hearing aid for high frequency sounds. The fourth objective was to understand the effect of the duration of therapy attended by the children wearing $\mathrm{CI}$ and Hearing Aid. The results from Tables 4-6 suggest that longer the therapy was attended, the better the learning. The scores (CAP, high frequency sounds and level of understanding) for the cases that has attended therapy for longer duration are much better compared to that for the cases which has attended for much lesser duration. We can see from Tables 4-6 that case 1 has better score compared to case 2 and case 3 for children wearing CI and case 4 has better scores compared to that for case 5 and case 6 who are wearing hearing aid.

\section{Conclusion}

Language comprehension and expression are important in a child's life for his/her future living. Proper articulation and intelligibility in speech are important for communication, where in AVT plays a major role in the acquisition of language. So, it is important that the child hears all the sounds of the word (high, mid and low frequency sounds) to acquire and articulate correct language. As we have seen, in case of CI wearing children sound is transmitted directly to the inner ear and then to the auditory nerve bypassing the outer and middle ear. Whereas, in case of hearing aids sound is not transmitted directly and has longer pathway for sound transmission. Hence, this results in the delay of information flow in case of hearing aids as compared to that of CI. Better hearing helps to understand and learn language in a much easier way. From the current study, we can conclude that children wearing $\mathrm{CI}$ are much more benefitted compared to that of children wearing Hearing aids. However, there are some limitations to the current study. First, the relatively small sample size of participants limited the current study to detect the performance of hearing impaired children with hearing aid and CI in AVT, while additional participants would have strengthened the findings. Second, the study was done on a group of children whose age range was less than 5 years old, so it could be that older children (of more than 5 years old) with hearing aid could have performed better than children implanted with CI. Third, the study was done on cases having a pure sensorineural component. Thus, we cannot comment about the performance of the cases having mixed hearing loss. Finally, the test used in the study was only one, that is 'CAP', which had a limited set of questions. Despite these limitations, the research goes some way towards providing a benchmark for the better performance of children with CI compared to that of children with hearing aid in AVT. This study has provided a research model, and this should be replicated in future studies and also more methodological approaches should be used to have a better understanding about the performance with CI and hearing aid in AVT.

\section{References}

1 Skwarecki B (2013) Babies learn to recognize words in the womb. American Association for the Advancement of Science.

2 Dianne J, Van T (1993) Hearing loss, speech and hearing aids. Journal of speech, language and hearing research 36(2): 228-244.

3 Harrison M, Roush J (1996) Age of suspicion, Identification and intervention for infants and young children with hearing loss: A National study. Ear and Hearing 17: 55-62.

4 Yoshinaga Itano C, Sedey AL, Coulter DK, Mehl AL (1998) Language of early and later identified children with hearing loss. Official Journal of the American academy of pediatrics 102(5).

5 Andreas M (1986) Age at fitting of hearing aids and speech intelligibility. British Journal of audiology 20(2): 165-167.

6 Reinier P (1978) Auditory handicap of hearing impairment and the limited benefit of hearing aids. The Journal of the Acoustical society of America 63(2): 533-549.

7 Lunner $\mathrm{T}$ (2003) Cognitive function in relation to hearing aid use. International Journal of Audiology 42(Supp1): 49-58.

8 Theunissen SCPM, Rieffe C, Kouwenberg M, Soede W, Briaire JJ, et al. (2011) Depression in hearing impaired children. International Journal of Otorhinolaryngology 75: 1313-1317.

9 Stuart G, Graham N, Clous E (2003) Benefits from hearing aids in relation to the interaction between the user and the environment. International Journal of Audiology 42(sup1): 77-85.

10 Lunner T, Rudner M, Ronnberg J (2009) Cognition and hearing aids. Scandinavian journal of psychology 50(5): 395-403.

11 White MW, Merzenich MM, Gardi JN (1984) Multichannel Cochlear Implants channel interactions and processor design. Archives of Otolaryngology 110(8): 493-501. 
12 Connor CM, Craig HK, Raudenbush SW, Heavner K, Zwolan TA (2006) The age at which young deaf children receive cochlear implant and their vocabulary and speech-production growth: Is there an added value for early implantation. Ear and Hearing, 27: 628-644.

13 Sharma A, Nash AA, Dorman M (2009) Cortical development, plasticity and re-organization in children with cochlear implant. Journal of communication disorders 42: 272-279.

14 Sharma A, Dorman, MF, and Spahr AJ (2002) A Sensitive period for the development of the central auditory system in children with CI: Implications for age of implantation. Ear and hearing 23: 532-539.

15 Andrej K, Sharma A (2005) The influence of a sensitive period on central auditory development in children with unilateral and bilateral cochlear implant. Hearing research 203: 134-143.

16 Svirsky MA, Robbins AM, Kirk KI, Pisoni DB, Miyamoto RT (2000) Language development in profoundly deaf children with cochlear implant. Psychological science 11(2): 153-158.

17 Brennan Jones CG, White J, Rush RW, Law J (2014) Auditory Verbal Therapy for promoting spoken language development in children with permanent hearing impairments. Cochrane systematic reviewintervention (3): CD010100.

18 Bertram B, Pad D (1995) Importance of auditory verbal education and parent's participation after CI of very young children. The annals of Otology, Rhinology and Laryngology 166: 97-100.

19 Easterbrooks SR, ORourke CM, Todd NW (2000) Child and family factors associated with deaf children's success in AVT. The American journal of Otology 21: 341-344.

20 Jackson CW, Schatschneider C (2014) Rate of language growth in children with hearing loss an auditory-verbal early intervention program. American annals of the deaf 158(5): 539-554.

21 Hogan S, Stokes J, White C, Tyszkiewicz E, Woolgar A (2008) An evaluation of AVT using the rate of early language development as an outcome measure. Deafness and education international 10(3): 143167.

22 Kates JM (2008) Digital hearing aids. Plural publishing. San Diego: Oxford Brisbane, USA.

23 Levitt H (2001) Noise reduction in hearing aids: A review. Journal of rehabilitation, research and development 38(1): 111-122.

24 Maxwell JA, Zurek PM (1995) Reducing acoustic feedback in hearing aids. IEEE Transactions on speech and audio processing 3(4): 304-313.

25 David B, Hawkins WY (1984) Signal-to-noise ratio advantage of binaural hearing aids and directional microphones under different levels of reverberation. Journal of speech and hearing disorders 49(3): 278-286.
26 House, WF (1976) Cochlear Implants. Annals of otology, Rhinology and Laryngology 85(Sup 3): 3-3.

27 Lendra MF, Robert VS, Deniz B, Xiaosong W (2001) Speech recognition in noise as a function of the number of spectral channels: comparison of acoustic hearing and cochlear implant. The journal of the acoustical society of America 110(2): 150-1163.

28 Wilson BS, Finley CC, Lawson DT, Wolford RD, Eddington DK, et al. (1991) Better speech recognition with CI. Nature 352(6332): 236-238.

29 Van Hoesel RJM, Tyler RS (2003) Speech perception, localization and lateralization with bilateral CI. The journal of the acoustical society of America 113(3): 1617-1630.

30 Tyler RS, Parkinson AJ, Wilson BS, Witt S, Preece JP, et al. (2002) Patients utilizing a Hearing aid and a cochlear implant: speech perception and localization. Ear and hearing 23: 98-105.

31 Dornan D (1999) Let's hear and say: Current overview of AVT. Asia pacific Journal of speech, language and hearing, 4(2): 141-154.

32 Dornan D, Hickson L, Murdoch B, Houston T, Constantinescu G (2010) Is AVT effective for children with hearing loss? Volta review 110(3): 361387.

33 Lim SYC, Simser J (2005) AVT for children with hearing impairment. Annals Academy of Medicine Singapore 34: 307-312.

34 Rhoades EA (2006) Research outcomes of auditory-verbal intervention: Is the approach justified? Deafness and education international 8(3): 125-143.

35 Fairgray E, Purdy SC, Smart JL (2010) Effects of AVT for school aged children with hearing loss: An exploratory study. Volta review 110(3): 407-434.

36 Archbold S, Lutman ME, Marshall DH (1995) Categories of auditory performance. Annals of Otology Rhinology and Laryngology 166: 312314.

37 Tomblin JB, Spencer L, Flock S, Tyler R, Gantz B (1999) Language learning with Cochlear implants compared to Hearing aid. Journal of Speech, Language and Hearing Research 42(2): 497-509.

38 Stelmachowicz PG, Pittman A, Hoover B, Lewis D (2004) Novel-word learning in children with normal hearing and hearing loss. Ear and Hearing 25(1): 47-56

39 Lierde KMV, Vinck BM, Baudonck N, Vel ED, Dhooge I (2005) Comparison of the overall intelligibility, articulation, resonance and voice characteristics between children using Cochlear implants and those with bilateral hearing aids. International Journal of Audiology 44(8): 452-465.

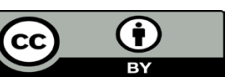

This work is licensed under Creative Commons Attribution 4.0 License

To Submit Your Article Click Here: Submit Article
DOI: $10.32474 /$ SJO.2019.02.000140

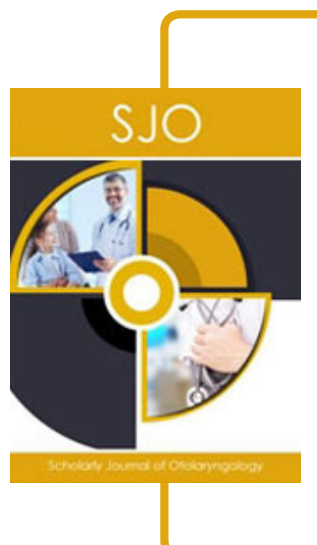

Scholarly Journal of Otolaryngology

\section{Assets of Publishing with us}

- Global archiving of articles

- Immediate, unrestricted online access

- Rigorous Peer Review Process

- Authors Retain Copyrights

- Unique DOI for all articles 